\title{
Selvmord Status Skjema - begrepenes relevans for akuttinnlagte suicidale pasienter og helsepersonells erfarte nytteverdi
}

\author{
Ved Martin Veland, Geir Tarje Bruaset og Fredrik A. Walby
}

\begin{abstract}
Å predikere hvem som kan komme til å ta sitt eget liv er svært vanskelig, både fordi selvmord er et relativt sjeldent fenomen og fordi kjente risikofaktorer har lav sensitivitet og lav spesifisitet (Mork, Mehlum, Walby 2009). Dette vil i mange tilfeller føre til usikkerhet i vurderingen av den aktuelle risikoen for selvmord. Selvmord Status Skjema (SSF) er et skjema som brukes for å kartlegge og tematisere selvmordsproblematikk med fokus på struktur og samarbeid mellom pasient og terapeut. Skjemaet kan være et godt hjelpemiddel både for den erfarne kliniker og helsepersonell som har mindre erfaring med denne type problematikk.
\end{abstract}

\section{ABSTRACT}

På Lovisenberg Diakonale Sykehus er det gjennomført et prosjekt for å undersøke hvorvidt Selvmord Status Skjema (SSF) er hensiktsmessig å bruke i akuttpsykiatrisk setting. Prosjektet har hatt til hensikt å unders $\varnothing$ ke hvordan lidelsestrykk gjenspeiler seg når pasienter vurderer lidelse ut fra opplevelse av psykisk smerte, stress, indre uro, håpløshet og selvhat, som er fem psykologiske begreper i SSF. Psykometriske egenskaper ved SSF og inter-rater reliabiliteten til kodemanual for kvalitative beskrivelser er undersøkt. I hvilken grad SSF er vurdert å være et nyttig verkt $\varnothing y$ er unders $\varnothing \mathrm{kt}$ fra perspektivet til miljøpersonell og behandlere.

Resultater: Det ble funnet et gjennomsnittlis høyt lidelsestrykk hos utvalget. Den interne validiteten mellom begrepene ble unders $\varnothing \mathrm{kt}$, og korrelasjonsforholdet mellom begrepene viste seg å være godt innfor akseptable verdier. Inter-rater reliabilitet for kvalitative variabler var lav. Både miljøpersonell og behandlere opplever SSF som et hensiktsmessig verktøy til bruk på en akuttpsykiatrisk sengepost.

Lovisenberg Diakonale Hospital completed a project to investigate whether Suicide Status Form (SSF) is appropriate to use in the acute psychiatric setting. The project has been designed to examine how suffering is reflected from the psychological experience of psychological pain, stress, agitation, hopelessness and selfhate, which is the five psychological concepts in the SSF. Psychometric properties of the SSF and inter-rater reliability of the code manual for qualitative descriptions are investigated. To what extent SSF is considered to be a useful tool is examined from the perspective of nursing staff and therapists.

Results: We found an average high level off suffering in the sample. The internal validity of the concepts were investigated, and the correlational relationship between the concepts proved to have acceptable values. Inter-rater reliability for qualitative variables was low. Both the nursing staff and therapists find SSF appropriate to use in an acute psychiatric setting.

MOTTATT: $\quad 06.01 .12$ REVIDERT: 11.04 .12 AKSEPTERT: 11.04.12

\section{Innledning}

Brown (2007) har laget en oversikt over tilgjengelige instrumenter til bruk for kartlegging og vurdering av selvmordsfare. Instrumentene i denne oversikten har både god validitet og reliabilitet, men altså lav sensitivitet og særlig spesifisitet (Brown 2007). Unders $\varnothing$ kelser har vist at slike instrumenter sjelden brukes rutinemessig i klinisk praksis (Jobes et al. 2004, Jobes 2006). Jobes og kolleger (1997) utviklet et instrument til klinisk bruk i vurdering av selvmordsrisiko. Instrumentet kalles Suicide Status Form (SSF) og er en sentral del i det manualbaserte behandlingsopplegget CAMS (Collaborative Assessment and Management of Suicidality) (Jobes 2006). Instrumentet vurderer både kvantitative og kvalitative aspekter ved selvmordsfare (Conrad 2009) og er i følge Range (2005) et av de mest utbredte instrumenter i klinisk praksis i USA. SSF er oversatt til flere språk, og studier har funnet gode psykometriske egenskaper i forhold til skjemaets interne validitet (Jobes 1997), interrater reliabilitet (Jobes 2004) og konvergerende validitet (Conrad 2009). En studie har foretatt inter-rater reliabilitetsanalyse ved bruk av kodemanualen som er utviklet av Jobes (2004). Denne viser at kodemanualen fungerte godt ved koding av beskrivelser fra suicidale pasienter i poliklinisk behandling $(\mathrm{k}=.88)$ (Jobes 2004). De fem psykologiske begrepene i SSF er i hvilken grad pasienten opplever belastning i forhold til psykisk smerte, stress, indre uro, håpløshet og selvhat. Pasientene skårer hver og en av dimensjonene kvantitativt på en skala fra 1 til 5. Etter hver kvantifisering, bes pasienten kort kvalitativt beskrive hva som representerer tallverdien.

\section{Håndtering av suicidalitet ved akuttpsykiatrisk avdeling}

Den hyppige forekomsten av ulike former for suicidal atferd på akuttpsykiatriske avdelinger, samt den sterkt $\varnothing \mathrm{kte}$ selvmordsfaren i denne populasjonen, medfører flere utfordringer i forhold til å utvikle og opprettholde gode rutiner for vurdering og terapeutiske tilnærminger rettet mot denne gruppa. En av de miljøterapeutiske oppgavene på akuttpsykiatrisk avdeling er å observere og kartlegge symptomer hos pasienter med selvmordsproblematikk. En unders $\varnothing$ kelse av sykepleiere på akuttpsykiatrisk inntakspost ved Lovisenberg Diakonale Sykehus viste at det var behov for mer aktive, standardiserte og systematiserte prosedyrer for kartlegging av selvmordsfare (Veland \& Walby 2010). I unders $\varnothing \mathrm{k}$ elsen fremkom det også at det var betydelige individuelle forskjeller i forhold til hvordan observasjon og kartlegging av symptomer hos pasienter med selvmordsproblematikk ble utf $\varnothing \mathrm{rt}$. Sykepleierne opplevde å mangle en prosedyre i tilknytning til denne viktige oppgaven (ibid). En standardisert prosedyre for kartlegging av selvmordsfare vil kunne f $\varnothing$ re til at kvaliteten på utførelsen av denne oppgaven vil bli på et høyere og jevnere nivå, og slik bidra til å kvalitetssikre behandlingen av suicidale pasienter (Veland 2009). Posten har $\varnothing$ nsket å finne en prosedyre som er egnet til å administreres av miljøterapeuter til bruk i daglig klinisk praksis. Flere skjemaer som kartlegger ulike områder innfor suicidalitet ble vurdert i forbindelse med utvikling av den nye prosedyren. Suicide Status Form (SSF) ble valgt på bakgrunn av bakenforliggende behandlingsfilosofi som brukermedvirkning, samarbeid og fokus på en behandlingsorientert dialog. 


\section{$\underline{\text { SSF }}$}

Pasient:

Kontakt:

Dato:

Tid:

Score og fyll ut hvert punkt i forhold til hvordan du har det nå.

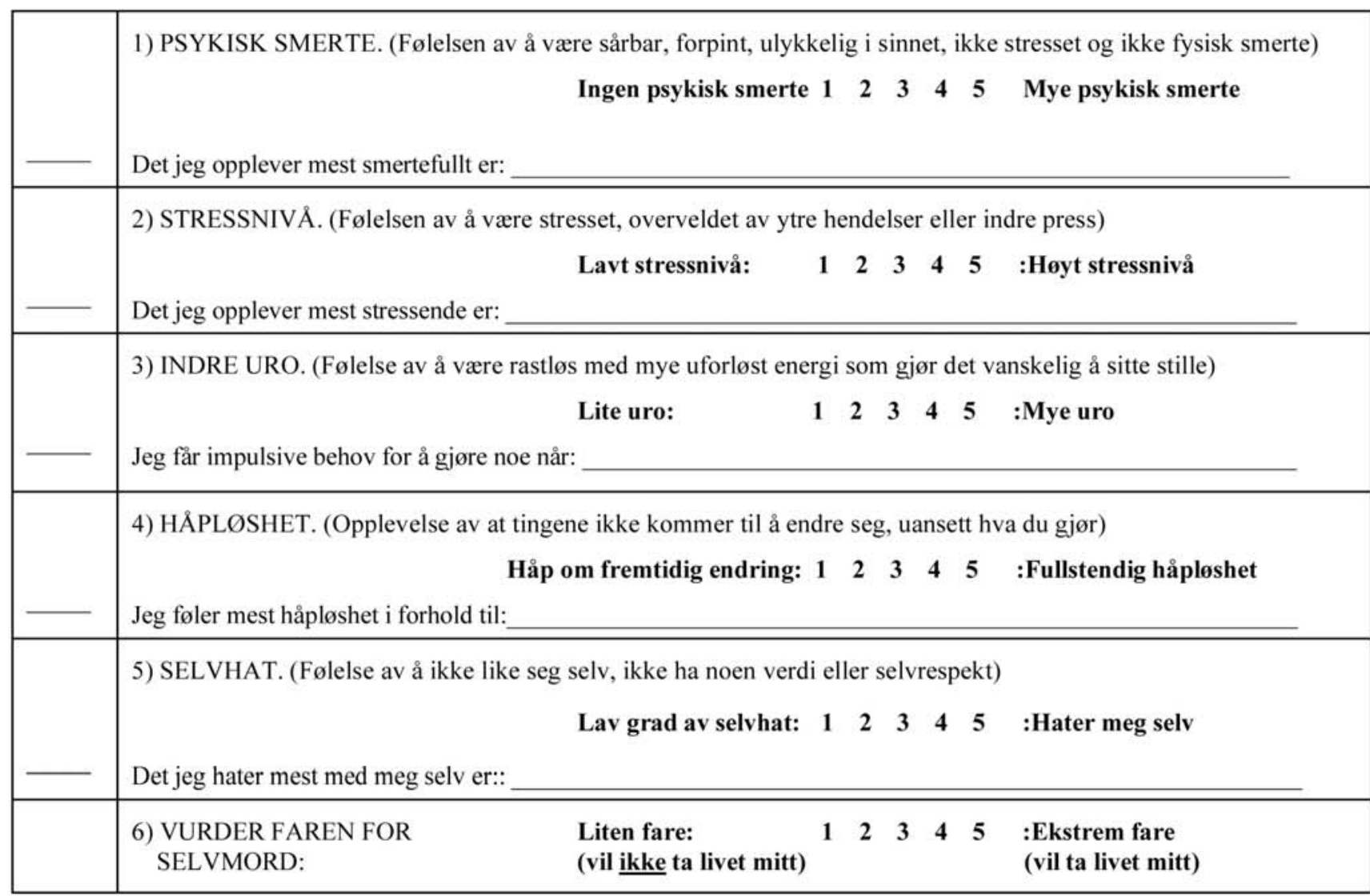

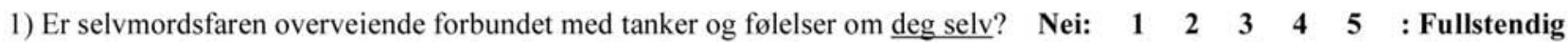

2) Er selvmordsfaren overveiende forbundet med tanker og følelser om andre? $\quad \begin{array}{llllllll}\text { Nei: } & \mathbf{1} & \mathbf{2} & \mathbf{3} & \mathbf{4} & \mathbf{5} & \text { : Fullstendig }\end{array}$

\begin{tabular}{|l|l|l|l|}
\hline & GRUNNER FOR $\AA$ DØ & & \\
\hline & & & \\
\hline & & & \\
\hline & & & \\
\hline & & & \\
\hline & & & \\
\hline
\end{tabular}

Jeg ønsker å dø:

Jeg ønsker å leve:

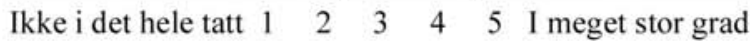

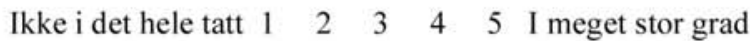

Jeg har tanker om å avslutte livet mitt: Aldri

Sjeldent

Noen ganger

Ofte

Hele tiden

Den ene tingen som kunne hjelpe meg til ikke lenger føle meg selvmordstruet ville være: 
Den nye prosedyren ble evaluert gjennom et prosjekt på akuttpsykiatrisk inntakspost ved Lovisenberg Diakonale Sykehus, i perioden september 2009 til august 2010.

Hovedmålet med prosjektet var å prøve ut hvordan SSF fungerer i norsk oversettelse og om instrument er egnet for bruk på en akuttpsykiatrisk sengepost. Det var også et mål å unders $\varnothing$ ke i hvilken grad SSF ble oppfattet som klinisk nyttig, både av sykepleiere som administrer prosedyren og av behandlingsansvarlige leger. I tillegg til å beskrive utvalgets lidelsestrykk ut fra begrepene i SSF, ble følgende tre problemstillinger studert:

1. Representerer begrepene i SSF selvstendige mål, og evner utvalget å skille mellom begrepene?

2. Fungerer kodemanualen for kvalitative beskrivelser godt når det ikke gis supplerende opplæring i kodeverket?

3. Hvilken opplevd nytteverdi har miljøpersonell og behandlere av SSF?

\section{Metode}

\section{Materiale}

Utvalget bestod av pasienter innlagt på akuttpsykiatrisk avdeling (AKU),

Lovisenberg Diakonale Sykehus i Oslo, og bestod av 59 kvinner med gjennomsnittsalder 35,4 år og 47 menn med gjennomsnittsalder 39,4 år. Kvinnene hadde flere tidligere innleggelser enn mennene. 43 pasienter(41\%) var førstegangs innlagt på AKU. Det var liten kjønnsmessig forskjell på gjennomsnitts liggetid på avdelingen (Tabell 1).
AKU tar imot pasienter som er i behov av фyeblikkelig hjelp hele døgnet. Pasientene er hovedsaklig innlagt etter henvisning fra Tøyen DPS, Lovisenberg DPS, Oslo kommunale legevakt eller fastlege. Det er brukt en autorisert norsk oversettelse (Veland \& Walby 2010) av Suicide Status Form - SSF (Jobes 2006). Pasienter som var frivillig innlagt med selvmordsproblematikk i innleggelsesgrunnlaget eller der hvor slik problematikk fremkom i innkomstsamtale, adferd eller meddelelser i posten, ble forespurt om å fylle ut SSF. Pasienter som var psykotiske og/eller synlig ruspåvirket ble ekskludert fra unders $\varnothing$ kelsen. I unders $\varnothing \mathrm{k}$ elsen om erfart nytteverdi ble helsepersonell spurt. Av miljøpersonell var det sykepleiere og spesialsykepleiere, samt en psykiatrisk hjelpepleier som ble spurt $(\mathrm{N}=13)$. Det var ansatte i full stilling og deltidsansatte. Av legene ( $=5)$ var det fire psykiatere og en lege i spesialisering som svarte.

\section{Prosedyre}

Ved innkomst ble pasienten tatt imot av vakthavende lege og sykepleier hvor det bl.a. ble foretatt en selvmordsrisikovurdering i tråd med Nasjonale retningslinjer for selvmordsforebygging i psykisk helsevern (2008). Bruken av SSF er ment å gi supplerende kartleggingsinformasjon, og hvilke pasienter som skulle gjennomgå SSF ble vurdert av sykepleier, lege eller psykiater. Det ble ikke registrert hvor mange pasienter som var aktuelle for gjennomgang av SSF i den aktuelle perioden. Det ble heller ikke registrert hvor mange som avslo gjennomgang, avbrøt gjennomgang eller hvor mange som ble ekskludert. Skjemaet ble administrert ved at sykepleierne i posten satt sammen med pasienten og veiledet og motiverte for utfyllingen. Pasienten var den som skrev ned svarene. Hvilke spørsmål som ble besvart, hvor lang tid utfyllingen tok og hvor mye pasienten $\varnothing$ nsket å formidle var opp til pasienten selv. I følge vår prosedyre skulle skjema brukes så raskt som mulig etter innleggelsen, men med forutsetning om at pasienten hadde fått tid til å samle seg noe. Pasienter som ble innlagt sent på kvelden eller i løpet av natten gjennomgikk derfor skjema påfølgende dag. Pasienten fylte ut SSF i papirformat. Deretter overførte sykepleier resultatene til en utarbeidet elektronisk versjon i avdelingens databaserte journalsystem, slik at informasjonen i SSF ble tilgjengelig for alt involvert behandlingspersonell.

Kvalitative beskrivelser tilknyttet de fem psykologiske begrepene fremkommer ved at pasienter fullfører følgende setninger: Det jeg opplever som mest smertefullt er: ..., Det jeg opplever som mest stressende er: ..., Jeg får impulsive behov for å gjøre noe når: ..., Jeg opplever mest håpløshet $i$ forhold til: ..., Det jeg hater mest med meg selv er: ... Kodemanualen (Jobes et al. 2004, 2006) inneholder en rekke kategorier som hver enkel beskrivelse kodes etter. For eksempel vil beskrivelsen "forholdet til min familie" bli kodet inn under kategorien relasjonell. (Det betyr at utsagnet handler om relasjonelle problemer.) Kvalitative beskrivelser knyttet til de fem psykologiske begrepene er kodet av to psykiatriske spesialsykepleiere. Beskrivelser fra 106 pasienter ble kodet fortløpende ved å knytte et tall til hver beskrivelse.

Tabell 1: Utvalg

\begin{tabular}{|c|c|c|c|c|c|c|c|c|c|c|c|c|}
\hline & \multicolumn{2}{|c|}{ Mann } & \multicolumn{2}{|c|}{$N \approx 47$} & \multicolumn{2}{|c|}{ Kvinne } & \multicolumn{2}{|l|}{$N \approx 59$} & \multicolumn{2}{|c|}{ Total } & \multicolumn{2}{|c|}{$V \approx 106$} \\
\hline & $\mathbf{M}$ & SD & Min & $\operatorname{Max}$ & $\mathbf{M}$ & SD & Min & Max & $\mathbf{M}$ & SD & Min & $\operatorname{Max}$ \\
\hline Alder & 39.4 & 13.4 & 19 & 79 & 35.4 & 12.9 & 19 & 68 & 37.2 & 13.2 & 19 & 79 \\
\hline Liggedøgn & 6.87 & 6.6 & 1 & 27 & 6.78 & 5.1 & 1 & 24 & 6.82 & 5.7 & 1 & 27 \\
\hline Innleggelser & 3.17 & 4.0 & 1 & 25 & 4.95 & 7.3 & 1 & 41 & 4.16 & 6.1 & 1 & 41 \\
\hline
\end{tabular}


Tabell 2: Gjennomsnittscore på de fem psykologiske begrepene i SSF

\begin{tabular}{|c|c|c|c|c|c|c|c|c|c|c|c|c|c|}
\hline & \multicolumn{4}{|c|}{ Mann } & \multicolumn{4}{|c|}{ Kvinne } & \multicolumn{5}{|c|}{ Total } \\
\hline & $\mathrm{N}$ & $\mathbf{M}$ & SD & Median & $\mathrm{N}$ & M & SD & Median & $\mathrm{N}$ & M & SD & Median & t-test \\
\hline Psykisk smerte & 47 & 3.89 & .98 & 4.0 & 58 & 4.24 & 1.0 & 5.0 & 105 & 4.09 & 1.0 & 4.0 & 0.079 \\
\hline Stress & 47 & 4.15 & .97 & 4.0 & 59 & 4.15 & 1.1 & 4.0 & 106 & 4.06 & 1.0 & 4.0 & 0.425 \\
\hline Indre uro & 45 & 3.73 & 1.0 & 4.0 & 56 & 3.32 & 1.3 & 4.0 & 101 & 3.50 & 1.2 & 4.0 & 0.092 \\
\hline Håpløshet & 47 & 3.62 & 1.1 & 4.0 & 58 & 4.02 & 1.1 & 4.0 & 105 & 3.84 & 1.1 & 4.0 & 0.085 \\
\hline Selvhat & 46 & 3.30 & 1.1 & 3.0 & 57 & 3.67 & 1.4 & 4.0 & 103 & 3.50 & 1.3 & 4.0 & 0.164 \\
\hline $\begin{array}{l}\text { Egenvurdert } \\
\text { fare for selvmord }\end{array}$ & 47 & 2.81 & 1.3 & 3.0 & 55 & 3.11 & 1.3 & 3.0 & 102 & 2.97 & 1.3 & 3.0 & \\
\hline
\end{tabular}

Dette tallet representerte en kategori i kodemanualen. Kodemanualen har en kort forklaring knyttet til hver av kategoriene, som er en forklaring på hva beskrivelsen skal inneholde for å falle inn under den bestemte kategorien. I tillegg gis det eksempler på beskrivelser som er typiske for kategorien. Utover forklaringen i selve kodemanualen, fikk ikke koderne opplæring.

\section{Opplevd nytteverdi av SSF}

Etter at SSF hadde vært benyttet i ett år på psykiatrisk akuttavdeling ble helsepersonell spurt om å evaluere skjema med fokus på opplevd klinisk nytteverdi. I denne unders $\varnothing$ kelsen ble informasjonen fra miljøpersonell og behandlere samlet inn ved bruk av spørreskjema. Av milj $\varnothing-$ personalet var det fire av de som ble spurt som ikke svarte på spørreskjema, mens alle behandlerne svarte.

\section{Etiske overveielser}

Studien ble godkjent av personvernombudet i henhold til helsepersonellovens $\S 26$, og er utført som en kvalitetskontrollstudie av prosedyrer og instrumenter som allerede var i bruk i behandlingen ved sykehuset. Informert samtykke fra den enkelte pasient ble derfor ikke innhentet.

\section{Resultater}

\section{Gjennomsnittscore på SSF-elementer}

Gjennomsnittsscoren på de fem psykologiske begrepene er høye. Median (4.0) viser at minst $50 \%$ av utvalget har angitt skåren 4 eller høyere på de fem psykologiske begrepene. Resultatene fra t-test viser at det ikke er signifikant forskjell på gjennomsnittscoren mellom kjønn. På psykisk smerte, indre uro og håpløshet ser man trender til at forskjellene er signifikant på $10 \%$ nivå (Tabell 2).

\section{Intern sammenheng mellom de fem} psykologiske begrepene i SSF

Spearman korrelasjonsanalyse mellom de fem psykologiske begrepene (Tabell 3) viser at ingen av korrelasjonene var veldig høye. Dette betyr at hvert av begrepene ikke er overflødige i forhold til hverandre eller avhengige av hverandre.

\section{Inter-rater reliabilitet ved kvalitative} beskrivelsene

De kvalitative beskrivelsene ble kodet inn i kategorier og plassert i den kategorien som lå utsagnet nærmest. Av alle pasientene $(\mathrm{N}=106)$ var det til sammen 383 beskrivelser, fordelt på de fem psykologiske begrepene, som ble kategorisert. Gjennomsnitt på antall beskrivelser var 3.6 (SD 1.6) og median 4.0. Inter-rater reliabiliteten ble målt hvor enigheten mellom to kodere viste seg å variere fra dårlig $(\mathrm{k}=.20)$ til $\operatorname{god}(\mathrm{k}=.65)$.

Tabell 3: Inter element korrelasjon av SSF-begreper

\begin{tabular}{|c|c|c|c|c|c|}
\hline & 1 & 2 & 3 & 4 & 5 \\
\hline Psykisk smerte (1) & & $.419 * *$ & $.338 * *$ & $.421 * *$ & $.403 * *$ \\
\hline$N$ & & 105 & 101 & 105 & 102 \\
\hline Stress (2) & & & $.450 * *$ & $.246 * *$ & $.210 * *$ \\
\hline$N$ & & & 101 & 105 & 103 \\
\hline Indre uro (3) & & & & $.063 * *$ & $.240 * *$ \\
\hline$N$ & & & & 101 & 99 \\
\hline Håpløshet (4) & & & & & $.339 * *$ \\
\hline$N$ & & & & & 102 \\
\hline Selvhat (5) & & & & & \\
\hline$N$ & & & & & \\
\hline
\end{tabular}


Tabell 4: Inter-rater reliabilitet av kvalitative beskrivelser i SSF

\begin{tabular}{|l|c|c|}
\hline & N & Kappa \\
\hline Psykisk smerte & 86 & .547 \\
\hline Stress & 89 & .509 \\
\hline Indre uro & 70 & .203 \\
\hline Håpløshet & 73 & .586 \\
\hline Selvhat & 66 & .654 \\
\hline Total & 383 & .500 \\
\hline
\end{tabular}

Indre uro skiller seg ut som den variabelen med laveste enighet mellom koderne (Tabell 4).

\section{Opplevd nytteverdi av SSF}

Alle behandlerne og 12 av 13 (92\%) av miljøpersonalet svarer at SSF oppleves som et nyttig verkt $\varnothing y$ for å komme i dialog rundt pasientenes suicidalitet. Prosedyren vurderes også som anvendelig i praksis. 4 av 5 behandlere og 12 av 13 av miljøpersonalet svarer at SSF er godt egnet til å få frem pasientens refleksjoner og opplevelse av suicidalitet. I tillegg svarer miljøpersonalet at SSF bidrar til at kartleggingen blir mer systematisk og standardisert. Alle behandlerne og 8 av $13(61.5 \%)$ av miljøpersonalet mener at SSF er godt egnet til å få frem informasjon som kan bidra til å få et bedre bilde av hva som er aktuelle problemer ved selvmordsproblematikk. Alle behandlerne og 10 av 13 (77\%) av milj $\phi$ personalet svarer at SSF bør fortsette som prosedyre etter at prosjektet er ferdig.

\section{Diskusjon}

\section{Opplevelse av lidelse - ulike terskler}

Utvalget i denne studien, bestående av akutt innlagte pasienter med suicidalitetsproblematikk, er en høyrisikogruppe for suicidal atferd og må også antas å ha stor grad av andre psykiske plager. Det er derfor ikke overraskende at vi fant et høyt gjennomsnittlig lidelsestrykk.
Når det gjelder begrepene i SSF, ser det ut til at kvinner og menn opplever belastning nokså likt når dette utrykkes tallmessig. De tallmessige utrykkene kan likevel være vanskelige å oversette til et klinisk anvendbart språk som forklarer pasientens opplevelse av tilstanden. Hvilke svar pasienten gir i SSF vil kunne være påvirket av ulike faktorer og pasienter vil derfor også kunne fremstå med ulike lidelsesuttrykk, selv om de har angitt samme score. En pasient som angir høyeste score på psykisk smerte vil samtidig kunne oppleve å håndtere denne tilstanden, mens en annen pasient med samme score vil kunne oppleve tilstanden som uutholdelig. Selv om teorien til Shneidman (1993) sier at selvmordsfaren er overhengende når psykisk smerte, stress og indre uro er på sitt høyeste, vil det ut fra overnevnte resonnement være vanskelig å overføre dette til å gjelde høy score i SSF isolert sett.

\section{Er begrepene relevante for dette utvalget?}

Vi fant gjennomgående lavere korrelasjoner mellom de ulike begrepene i SSF enn hva Conrad (2009) gjorde. Våre funn gir holdepunkter for at de fem begrepene er relativt uavhengige mål og ikke overflødige i forhold til hverandre. Det tyder også på at SSF er utformet slik at også informanter med så høy problembelastning som i dette utvalget, er i stand til å skille mellom begrepene. De rapporterte skårene er derfor ikke bare et uttrykk for et generelt lidelsestrykk. At hver kvantifisering ettersp $\varnothing r$ en beskrivelse (f.eks: "det jeg opplever som mest smertefullt er: ...") vil kunne ha en modererende effekt på hvor høyt variabelen skåres. At pasientene på forhånd blir forklart viktigheten av å gi beskrivelser i tillegg til scoringsverdien, kan bidra til at pasienten tenker seg ytterliggere om før skåren angis og klarer å differensiere mellom ulike følelser og opplevelsesaspekter.

\section{Å tolke beskrivelsene i SSF}

Resultatene som angår enigheten mellom koderne sett under ett $(\mathrm{k}=.50)$, vurderes å være for lavt i forhold til kodemanualens statistiske formål.
Dette er et resultat som er klart lavere enn hva et tidligere studie har funnet $(\mathrm{k}=.88)$ (Jobes 2004). En forklaring på dette, kan være den betydelige forskjellen på utvalgene mellom studiene. Man kan anta at polikliniske pasienter gjennomgående formulerer utsagn som lettere lar seg plassere inn i de bestemte kategoriene enn akuttinnlagte pasienter. Høyere enighet mellom koderne i Jobes' studie, kan også være et resultat av at opplæringen er gitt av de som utviklet kodemanualen, og som derfor hadde god erfaring med å kode utsagn. I denne studien fikk ikke koderne opplæring utover hva som er beskrevet i kodemanualen. Noen pasienter er overveldet av et emosjonelt lidelsestrykk med en begrenset evne til refleksjon, mens andre har en klar oppfatning av hvilke faktorer som påvirker. Ut fra våre resultater kan man argumentere for at kodemanualen ikke bør brukes kvantitativt uten at det er gitt omfattende opplæring både i forhold til koding og hvordan man praktisk anvender SSF. Det er viktig å presisere at beskrivelsene ikke utelukkende er avhengig av god inter-rater reliabilitet for å tjene sin kliniske hensikt. Dersom informasjonen som ligger i beskrivelsene er spesifikk og konkret, vil denne uansett kunne være egnet til å gi en bedre forståelse av den enkelte pasientens suicidale tanker.

\section{Opplevd nytteverdi for miljøpersonell og behandlere}

Tilbakemeldingene fra behandlere og miljøpersonalet er positive når det gjelder evaluering av skjemaets egenskaper som form og innhold. Både miljøpersonalet og behandlere opplever samtidig at skjemaet i seg selv er et nyttig verkt $\varnothing$ y å bruke sammen med suicidale pasienter. For miljøpersonalet er dette en ny tilnærming i forhold til det å kartlegge selvmordsfare. Det vil også være grunn til å tro at den nye prosedyren har bidratt med å gi bedre forutsigbarhet. For behandlere vil prosedyren gi bedre forutsigbarhet i forhold til miljøpersonalets bidrag til kartleggingen av selvmordsfare. Behandlerne ser ut til å anse den nye prosedyren som et nyttig supplement til den helhetlige vurderingen som de er ansvarlige for. 
For de som leser pasientens svar uten selv å ha vært tilstede når skjemaet ble gjennomgått, vil den kliniske kvaliteten være avhengig av pasientens evne til å beskrive sin tilstand. Et skjema som bare inneholder kvantitative data, vil gi mindre informasjon enn et skjema som også inneholder kvalitative beskrivelser. Man vil derfor være opptatt av å få frem klinisk relevante opplysninger som kan benyttes i behandlingen. Respondentene i denne studien har gjennomgått SSF såpass tidlig i behandlingsforløpet at det ofte ikke har vært utfyllende opplysninger knyttet til pasientens opplevelse av suicidalitet fra $\varnothing \varnothing r$. Bruk av SSF tidlig i behandlingsforløpet har derfor kunnet gi behandlerne en bedre oversikt over pasientens suicidale problemer.

Den praktiske erfaringen ved bruk av SSF har vært at prosedyren oftest tar

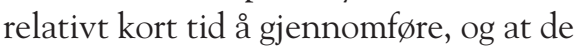
aller fleste pasientene fullfører skjemaet uten større problemer. Dette er faktorer som, i en akuttpsykiatrisk sammenheng, får SSF til å fremstå mer anvendelig enn

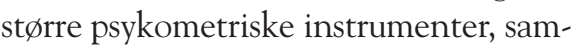
tidig som man ivaretar styrkene ved en strukturert prosedyre. Vi ser at pasientene benytter seg av muligheten til å formulere egne beskrivelser, noe som forteller mye om hvilke problemer pasienten anser som betydningsfulle i den aktuelle situasjonen. Implementeringen av SSF som prosedyre har også ført til at kartlegging av suicidalitet hos innlagte pasienter på en travel akuttpsykiatrisk avdeling i mindre grad baseres på individuelle ferdigheter, interesse for og kunnskaper om suicidalitet, og på den måten blitt mer systematisk i tråd med føringene i de nasjonale retningslinjene (Sosial- og helsedirektoratet 2008).

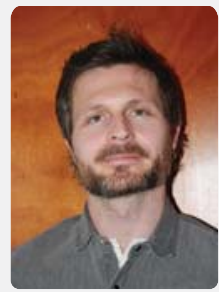

Martin Veland er avdelingssykepleier ved psykiatrisk akuttavdeling, Lovisenberg Diakonale Sykehus. Han har mastergrad i psykososialt arbeid med studieretnig selvmordsforebygging fra $\mathrm{UiO} / \mathrm{NSSF}$.

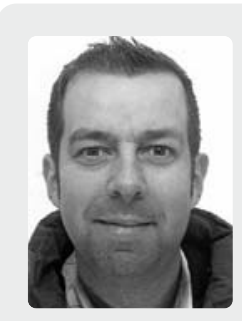

Geir Tarje Bruaset er spesialsykepleier ved psykiatrisk akutt avdeling, Lovisenberg Diakonale Sykehus.

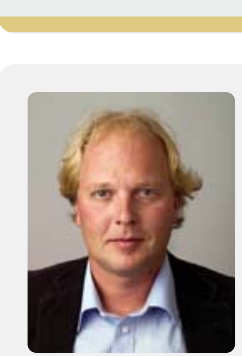

Fredrik A. Walby er sjefpsykolog ved Psykiatrisk avdeling, Diakonhjemmet sykehus og forsker ved NSSF. Han har vært sentral $\mathrm{i}$ arbeidet med utarbeidelse og implementering av kliniske retningslinjer for selvmordsforebygging i psykisk helsevern, har undervist og publisert forskningsarbeider innen klinisk suicidologi. Walby er også teamleder for et DBT-team.

\section{Referanser}

Altman, D. (1991). Practical statistics for Medical research. London: Chapman and Hall.

Baumeister, R. F. (1990). Suicide as Escape From Self. American Psycological Association Inc. (90-113).

Beck, A.T., Brown, G.K., Berchick, R.J., Stewart, R.A., \& Steer, R.A. (1990). Relationship between hopelessness and ultimate suicide: A replication with psychiatric outpatients. American journal of psychiatry 147, (190-195).

Beck, A.T., Steer, R.A., Kovacs, M., \& Garrison, B. (1985). Hopelessness and eventual suicide: A 10-year prospective study of patients hospitalized with suicide ideation: Psychometric properties of a self-report version. Journal of clinical psychology, 44, (499-505).

Brown, G. (2007). A Review of Suicide Assessment Measures for Intervention Research with Adults and Older Adults. Funnet på: www.suicidology.org/c/document_library/get_file?folderId

Cavanagh, J-TO., Carson, A., Sharpe, M. et al. (2003). Psychological autopsy studies of suicide: a systematic review. Psychol Med; 33, (395-405).

Conrad, A. K. et al. (2009). A Psychometric Investigation of the Suicide Status Form II with a Psychiatric Inpatient Sample. Suicide and LifeThreatening Behavior 39 (3) June. The American Association of Suicidology.

Jobes, D. A., Jacoby, A. M., Cimbolic, P., \& Hustead, L. A, T. (1997). Assessment and treatment of suicidal clients in a univercity counseling center. Journal of Counseling Psychology, 44 (368-377).

Jobes, D. (2004). Describing Suicidality: An Investigation of Qualitative SSF Responses. The American Association of Suicidology, 34, (99-112).
Jobes, D. (2006). Managing Suicidal Risk, A Collaborative Approach. The Guilford Press.

Linehan, M. M. (1997). Behavioral treatments of suicidal behaviors: Definitional obfuscation and treatment outcomes. In D. M. Stoff \& J. J. Mann (red.), Neurobiology of suicide. New York: Annals of the New York Academy of Sciences.

Mork, E., Mehlum, L., \& Walby, F. (2009). Selvmord ved depresjon med psykotiske symptomer og bipolar lidelse: forekomst, risikofaktorer og nevrobiologiske forhold. Suicidologi, 14 (2) $(8-11)$.

Range, L. M. (2005). The family of instruments that assess suicide risk. Journal of psychopathology and Behavioral Assessment, 27 (133-140).

Ruud, T., Gråve, R., \& Hatling, T. (2006). Akuttpsykiatrisk behandling i Norge - resultater fra en multisenterstudie (SINTEF - rapport A310). Trondheim: SINTEF Helse.

Paris, J. (2007). Half in love with death. Lawrence Erlbaum Associates, Inc.

Pearson, J.L., Stanley, B., King, C.A., \& Fisher, C.B. (2001). Intervention research with persons at high risk for suicidality: Safety and ethical considerations. Journal of Clinical Psychiatry, 62 (25) (17-26)

Qin, P., Agerbo, E., Mortensen P. B. (2003). Suicide risk in relation to socioeconomic, demographic and familial factors: a national register-based study of all suicides in Denmark, 1981-1997. Am J Psychiatry, 160 (765-772).

Statistisk Sentralbyrå d $\phi$ dsårsaker. Statistikk ble funnet på: http://www.ssb.no/emner/03/01/ 10/dodsarsak/

Shneidman, E. (1993). Suicide as psychache; a clinical approach to self-destuctive behavior. Northvale, NJ: Aronson

Sosial- og helsedirektoratet (2008). Nasjonale retningslinjer for forebygging av selvmord $\mathrm{i}$ psykisk helsevern (IS-1511). Oslo: Sosial- og helsedirektoratet.

Veland, M.C. (2009). Selvmord Status Skjema - en mulighet for pasienter å utrede sin suicidale tilstand? Prosjektoppgave, Videreutdanning i selvmordsforebyggende arbeid, UIO.

Veland, M.C., Walby, F.A. (2010). Implementering av Suicide Status Form på akuttpsykiatrisk avdeling. Suicidologi, 15 (3) (17-19)

Walby, F. A., Odegaard, E., Mehlum, L. (2006). Psychiatric comorbidity may not predict suicide during and after hospitalization. A nested case-control study with blinded raters. Journal of Affective Disorders 92 (253-260).

Walby, F. A., Odegaard, E., \& Mehlum, L. (2005). Risk Factors for completed suicide in psychiatric inpatients. In XXIIIth Congress of International Association for Suicide Prevention, Durban. 